\title{
Student perceptions of successful learning support for an international high school programme: a comparative case study in Turkey
}

\author{
Öykü Dulun ${ }^{\ddagger}$, Jennie F. Lane (iD and Armağan Ateşkan
}

Graduate School of Education, Bilkent University, Ankara, Turkey

\begin{abstract}
This study used comparative case study methodology to investigate student perceptions of different programmes that prepare them for a challenging high school education programme: the International Baccalaureate Diploma Programme (IBDP). Given the benefits and challenges of the programme, educators and stakeholders want to ensure students feel ready to participate. In the literature, studies support that programmes such as the International General Certificate of Secondary Education and the International Baccalaureate Organisation's Middle Years Programme prepare students for the IBDP; however, there is a need for students' voices on how they perceive they are prepared through these programmes. This study investigated three different approaches to IBDP preparation by gaining student insights through a scaled-item questionnaire and interviews. Students identified experiences that gave them skills to monitor their learning and resources that motivated them to participate in an advanced upper-high school programme.
\end{abstract}

\section{KEYWORDS}

Affective domain; cognitive domain; International Baccalaureate Diploma Programme; international education; student perceptions

\section{Introduction}

Among the knowledge and skills youth will need to succeed in the globalised twenty-first century is the appreciation and understanding of other cultures (Wright and Lee 2014). International education programmes have a curriculum that promotes international mindedness and global awareness (Gellar 2002; Thompson 1998). These programmes promote global citizenship and respect for cultural thoughts, beliefs and values (Cambridge 2012; Tate 2013). One organisation that features international education and fosters international mindedness is the International Baccalaureate Organisation (IBO). The IBO offers a continuum of programmes that challenge students in their academic studies and personal development (IBO 2017b). These programmes are for all grades, including one for the last two years of high school (upper-high school), called the IB Diploma Programme (IBDP).

The IBDP is an interdisciplinary programme that emphasises the process of learning rather than the product (Ateşkan et al. 2014). Several studies have highlighted the positive outcomes of IBDP students (Bagnall 2010; Hill 2012; Wright and Lee 2014). Suldo, 
Shaunessy and Hardesty (2008) note that IBDP is an extremely demanding programme with enormous benefits. Their study found that IBDP students were academically more successful compared to their peers who were studying within a national curriculum. In Turkey, Author 3 et al.(2014) reported that compared to students who only experienced the Turkish curriculum, students who received an IBDP certificate completed their university schooling in a timelier manner.

Being a successful IBDP student does not come without costs. The heavy workload and academic expectations cause high levels of stress (Foust, Hertberg-Davis, and Callahan 2009). Suldo, Shaunessy and Hardesty (2008) examined the relationships among stress, coping and mental health of high-achieving high school students and learned that IBDP students reported having high levels of stress. Given the benefits of IBDP along with the challenges, there have been discussions on how best to prepare students to be successful in IBDP (ACER 2015; Ateşkan et al. 2014; Bagnall 2010). The current study collected data from students from three different schools that offer the IBDP. While the schools have comparable demographics, they each have different approaches to IBDP preparation in grades 9 and 10. Student perceptions about their experiences provided the researchers with suggestions that will support student preparation for any rigorous high school programme.

\section{Research context and review of related literature}

As noted above, the IBDP is offered in grades 11 and 12 (upper-high school). During the time at which this study was conducted, there were 57 IBO world schools in Turkey, 39 of which were offering the IBDP (IBO 2017). Most of these schools $(n=27)$ are located in Turkey's two largest metropolitan cities: Istanbul and the capital, Ankara. In Turkey, schools that offer IBDP follow one of three approaches to prepare students in grades 9 and 10 (lower-high school) for their upper-high school international education. In the current paper, these approaches are called pre-IBDP programmes and include the following:

\section{- Pre-IBPD programme MoNEP}

All schools in Turkey are required to follow the national curriculum, which is administered by the Ministry of National Education (MoNE). The MoNE functions according to the common and specific aims and the general principles of the Turkish National Education System (MEB 2018). Schools that offer IBDP in addition to the national programme will provide students with enrichment activities in grades 9 and 10 to prepare them for the international programme.

- Pre-IBDP programme IGSCE

Some schools have opted to enhance their lower high school programmes, only offered in grades 9 and 10, by implementing the International General Certificate of Secondary Education (IGCSE). The IGCSE provides opportunities for contextualised learning and the content is flexible enough to suit a wide range of schools around the world (Cambridge 2018). There are over 6100 schools in 145 countries that offer the IGCSE; in Turkey there are 25 Cambridge schools (Cambridge 2016).

\section{- Pre-IBDP Programme MYP}

Some IBO world schools in Turkey offer the Middle Years Programme (MYP) that is implemented in grades 6 to 10. IBMYP has the goal of developing students' personal understanding, sense of self and responsibility in their community (IBO 2018b). 
There have been only a few studies that have investigated how these programmes prepare students for the IBDP. But there have been no studies to date, however, that compare the programmes to the Turkish national curriculum in terms of IBDP preparation. This gap in the literature leads to a need for further insights into how these pre-IBDP programmes and others can prepare students for advanced learning during their upper-high school years. Visser (2010) found through interviews with 21 MYP coordinators that the main reasons to adopt MYP were its educational philosophy and relatedness with IBDP. According to the study by Reimers (2004), there are no significant correlations between students' participation in MYP and student IBDP success. He notes that because MYP provides a curriculum framework and IBDP is more content-driven, students may not receive the skills they need to succeed in the rigorous high school programme. He acknowledges, however, that since MYP gives some flexibility as to how each institution implements the programme, this finding may be influenced by the quality of education of each particular school.

The Australian Council for Educational Research (ACER 2015) conducted a study of students in China, Hong Kong, India, Indonesia and Japan by examining the impact and influence of MYP on student IBDP outcomes. The findings show that the non-MYP students needed a 'bridge' to develop analytical and evaluative skills to study IBDP successfully.

Regarding IGCSE, Monteath (2015) reports that because of its international focus, there are an increasing number of schools that desire to implement IGCSE. Sagun and Çorlu (2014) notes that the IGCSE has an exam that may be good practice for IBDP exams. In 2014, Sagun and Çorlu compared MYP and IGCSE experience on students' IBDP science course and did not find a significant difference between the programmes. Other studies learned that MYP students obtain much better IBDP exam scores compared to non-MYP students (ACER, Australian Council for Educational Research 2015; Wade and Wolanin 2015).

These studies revealed interesting and sometimes conflicting findings regarding the merits of each programme. There have been no studies to date, however, that compare the programmes to the Turkish national curriculum in terms of IBDP preparation. The researchers were interested in learning how students perceive these programmes prepared them for IBDP, including similarities and differences. The purpose of the study was not to evaluate the programmes; instead the aim was to identify effective and less effective practices among the programmes to provide overall recommendations for the IBDP preparation.

\section{Theoretical framework and research questions for the study}

To frame the current study, the researchers focused on the IB's Approach to Learning (ATL), which identifies interrelated skills to help students learn how to learn (IBO 2017a). Therefore, the framework includes the cognitive and affective domains described below.

\section{Cognitive domain}

Metacognition and self-regulated learning were selected because there is a positive relationship between these attributes and effective learning strategies (Berk 2014). Furthermore, self-regulation supports academic performance (Yumuşak, Sungur, and Çakıroğlu 2007). Metacognition, thinking about thinking, is where students are aware of strategies they use to understand new concepts. Metacognitive strategies include rehearsal, elaboration and organisation (Pintrich and De Groot 1990; Pajares and Schunk 2001). Self-regulated 
learning is education where students are engaged with their own cognitive development and goal orientation (Zimmerman 2002). These include strategies such as setting goals, developing strategies to meet the goals, managing timelines and monitoring progress (Muis 2007).

\section{Affective domain}

The affective domain includes feelings, appreciation, enthusiasm, perceptions and values (Kirk 2009). Our study focused on motivation and attitudes that encourage school engagement. In a three-year study conducted on grade 9 and 10 students, Li and Lerner (2013) report that school engagement is essential to achieve high standards of academic achievement. They explain that positive and motivational thoughts are supportive to enhance cognitive capacity. Yang (2005) notes that effective learners are usually more voluntarily engaged, which helps them better encode, recall and comprehend information. Yang also highlighted how the cognitive and affective domains are interrelated. Motivation helps students become more goal-oriented and encourages them to become more engaged in their cognitive development. Other researchers discuss the importance of students having positive attitudes toward their studies to encourage them to actively monitor and regulate their learning (Pajares 1996; Pintrich and De Groot 1990; Schunk (1995).

Using educational theories associated with the cognitive and affective domain helped the researchers identify research methods, data sources and instruments to understand students' perceptions of their IBDP preparation. This framework guided the investigation to address the following research question and sub-questions (after each question the data source and analysis methods are provided):

(1) To what extent do students from different pre-IBDP programmes report they have strong self-regulated learning skills, metacognition, motivation, and attitudes toward learning in their preparation for IBDP? (Assessed through a questionnaire; descriptive statistics of means and frequencies of relevant data.)

We divided this main research question into the two sub-questions below:

(1a) Do students from different IBDP preparation experiences have significantly different perceptions of their self-regulated learning skills, metacognition, motivation and attitudes toward learning? (Assessed through an ANOVA of questionnaire responses.)

(1b) What pre-IBDP preparation experiences do students perceive helped them feel ready for IBDP? (Qualitative analysis of insights gained through focus groups.)

\section{Research methods}

This study used a comparative case study methodology (Yin 2002) to focus on three different private high schools. It involved mixed methods to provide an explanatory sequential design (Ivankova, Creswell, and Stick 2006). Data collection was designed to gather information about student perceptions of their IBDP preparation. While all three schools had similar IBDP success rates, the academic outcomes of individual students were neither collected nor relevant to the study. Students were first administered a self-reporting questionnaire (with Likert-type scaled items) and then, one month later, selected students participated 
in focus groups. Using mixed methods and multiple data sources helped triangulate the data since the researchers could look for convergence, corroboration and correspondence of results (Greene, Caracelli, and Graham 1989). For the current study, the qualitative data helped provide deeper insights into and clearer explanations of the quantitative findings.

Compared to other studies that have investigated pre-IBDP programmes, what is unique about the current study is that it focused on and highlights students' perspectives. CookSather (2002) describes this process as authorising students' perspectives - researchers consider what schools can learn from student voices since they are the ones who lived through the experiences. Since experiences influence how students learn, one of the best ways to learn about this influence is by asking them. The researchers recognise that any data gained from self-reporting instruments have inherent biases and misperceptions. The study is limited by student perceptions; nonetheless, it is these perceptions that were of value. Through the mixed methods and comparative analysis, the researchers focused on reporting findings that were frequently mentioned and strongly emphasised in the data.

\section{The cases}

Three schools (Cases) were selected for this case study. They all follow the IBDP for upperhigh school, but have different preparation programmes for students in grades 9 and 10 (lower-high school). The researchers sought to identify schools with similar demographics and IBDP performance rates. All schools are located in metropolitan areas (two in Ankara, one in Istanbul). All the students are ethnically Turkish; one school does enrol international students, but they were not included in the study. Being private schools, most of the students come from families of high socioeconomic status; nearly all their parents have graduated from college and many have advanced degrees.

- Case MoNEP

The MoNEP-IBDP School is in Ankara (the capital city), it was established in 1993 and has been recognised as an IBO world school since 2008. This school follows the national curriculum and courses are offered in Turkish. However, in preparation for the IBDP, science and mathematics are delivered in English.

- Case MYP

This school offers MYP to its students. It is an MYP-IBDP school in Istanbul (western Turkey) established in 1985 and has been recognised as an IBO world school since 1995. Most of their courses are offered in English.

- Case IGCSE

This school offers IGCSE in lower high school. IGCSE-IBDP School is in Ankara (capital city) and was established in 1994 and has been recognised as an IBO world school since 1996. Most of their courses are offered in English.

It may be noted that the Cases have been implementing the IBDP for varying numbers of years, with Case MoNEP having most recently been recognised as an IBO world school. Nonetheless, all cases have been offering IBDP for over 10 years and have successfully completed at least one evaluation by the IBO. The average IB diploma scores for the cases in this study were above the world average and further support the comparability of the schools. Out of a possible score of 45 for the IB diploma, students from Case IGCSE scored 
an average of 32 and Cases MYP and MoNEP had a mean score of 33 each. Another issue that may limit the study is that IBDP preparation programmes vary in length. The IGCSE is a two-year programme for the lower-high school level (grade 9 and 10), while the MYP is a five-year programme (grades 6 through 10). Furthermore, even though the study identifies one Case MoNEP school, students from all cases have experienced the MoNEP. This is because as Turkish students, they have been participating in the MoNEP throughout their schooling as all schools in Turkey are required to follow the national curriculum. During data collection, we asked students to focus on their lower-high school years, grades 9 and 10. Despite these limitations (school location, programme duration, shared national curriculum), the similarities among the Cases - private, prestigious schools, located in large cities - gave the researchers confidence that they could gain student perspectives about how the three programmes prepare students for the IBDP. Although the IBDP does not have any pre-requisites, schools would like to provide a curriculum and/or programme that is well-designed to improve particular skills in lower-high school students that will function as a bridge in their IBDP years. The schools were treated as separate units, although they were compared and contrasted with each other.

\section{Study population}

Data was collected from the following sample populations:

- Students in grade 10 who are currently enrolled in one of three pre-IBDP preparatory programmes

- Upper-high school students who are currently participating in the IBDP (grades 11 and 12)

Grade 9 students were not included in the study as they were just starting lower-high school and had very little experience in pre-IBDP programmes. Grade 10 students were aware of what was expected of them in IBDP and asked to share perceptions of preparation in their current and previous grade. Grade 11 students had been experiencing IBDP for several months and Grade 12 students were in their second year of IBDP. The upper-high school students were asked to reflect on their preparation in lower-high school and share thoughts on what worked to prepare them and what they felt needed improvement. The eleventh-grade students had a new awareness of what IBDP entailed, while the students in their second year had a more comprehensive understanding of the expectations and skills needed to be successful in IBDP. Participants from all three schools and grade levels are provided in Table 1.

\section{Instruments}

The questionnaire for this study was used to address the main research question and the first sub-question. It had four parts (Parts A, B, C, and D) with a total of 33 Likert-type scaled items. The instrument compiled scaled items from relevant and validated questionnaires that related to the theoretical framework. The parent questionnaires were the Motivated Strategies for Learning Questionnaire (MSLQ) and the Patterns of Adaptive Learning Scales (PALS). 


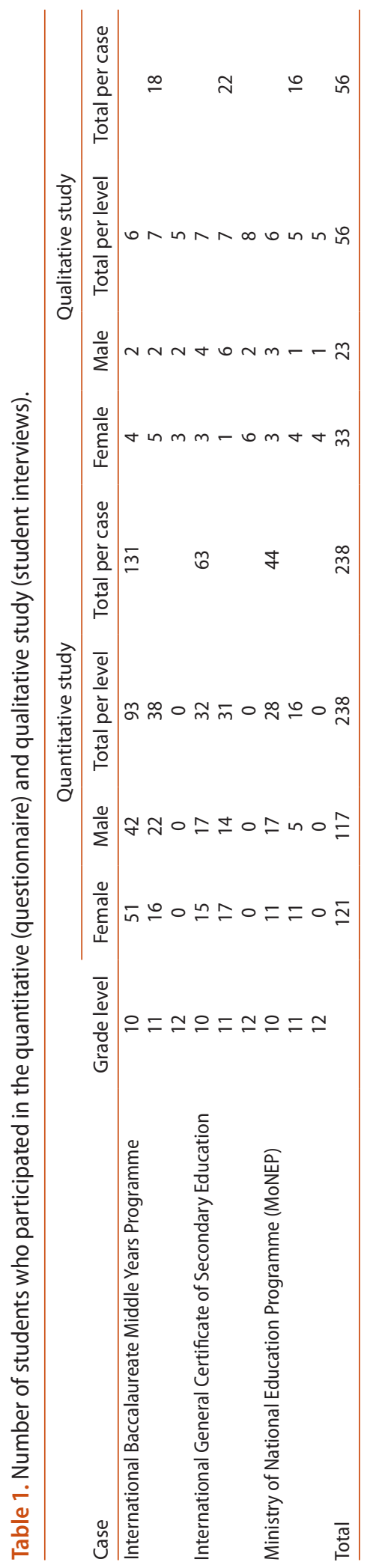


The MSLQ measures students' self-regulated learning strategies, metacognitive skills and motivational beliefs. It has been used in many countries, with students from primary school to university level. In 2000, the MSLQ was used by PISA to determine the effects of cultural similarities and differences of countries on strategies of motivation and learning. Another study, conducted in Turkey, used the MSLQ to determine the motivation levels and learning strategies of secondary education students. The instrument was administered by the Social Sciences and Humanities Research Group with support from the Scientific and Technological Research Council of Turkey and the Ministry of National Education Research and Development Department (Karadeniz et al. 2008). In the current study, 10 items in Part A, 8 in Part B and 9 in Part C came from the MLSQ and measured metacognition, self-regulation and motivation, respectively.

The fourth part of the questionnaire, Part D, included six items from PALS and measured attitudes toward learning. PALS is an effective tool that has been used with many populations and with a range of grade levels (Midgley et al. 2000). It was developed by researchers from Michigan University to examine how the learning environment and students' motivation levels and behaviours are related and has been used in several studies (Kitsantas, Steen, and Huie 2009; Mascret, Elliot, and Cury 2015; Matos et al. 2017; Ruzek et al. 2016).

The MSLQ has already been translated and validated in Turkish. The PALS items were translated by the third author and back-translated by a colleague to ensure the participants' understanding and to eliminate misinterpretations.

Construct validity and the reliability of the questionnaire were tested by using SPSS 20.0. A correlation analysis supported the construct validity of the questionnaire showing that the relationships between the variables are of the same construct. Internal consistency of all the items in questionnaire was checked by conducting a reliability analysis following the factor analyses. This analysis used the following factors that corresponded with the original version: metacognitive skills, self-regulation, motivation, attitudes toward learning. The Cronbach's alpha of Part A (10 items) was .870; of Part B (8 items) was .849; Part C (9 items) was .868; Part D (6 items) was .672.

The focus-group interview questions included open-ended questions that were designed to provide deeper insights into the quantitative data results; they were developed based on the preliminary data analysis of the questionnaire. To provide insights into sub research question $1 \mathrm{~b}$, the study participants were asked the following questions:

- How do you believe that MYP/IGCSE/MoNEP will prepare/prepared you for the assignments and tests in IBDP? (to gain insights into perception of readiness)

- What are the skills you have mastered through MYP/IGCSE/MoNEP that will help/ helped you to be successful in IBDP? (to gain insights into self-regulated learning skills and metacognition)

- Please describe your study habits and the environment (to gain insights into self-regulated learning skills and metacognition)

- What kind of course materials arouse your curiosity and desire to do research? (to gain insights into motivation and attitudes toward learning)

- How have you been able to use knowledge or skills you learned in one course in a different course? (to gain insights into motivation and learning)

The face validity of the items was ensured by piloting them with two high school students and one high school English teacher who were from a different school than the case study 
schools. This pilot involved separate interviews with each participant to allow for individual comments on the wording of the questions. After the test run, the items were revised as needed to ensure clarity and to avoid bias. The questions were given in Turkish since all of the participants were ethnically Turkish.

\section{Data collection}

Data collection started after receiving permission from the Turkish Ministry of National Education. The schools were contacted to secure their agreement to participate. The first author visited the case schools at a set time to administer the student questionnaire.

All students in grades 10 and 11 from the three case study schools successfully completed the questionnaire. The questionnaire aimed to collect data on recent perceptions of pre-IBDP experiences; therefore Grade 12 students were not included in the quantitative phase of the study. While the students were filling in the questionnaire the first author was there to answer any of the student's possible concerns and questions. Students completed the questionnaire within 15 to $20 \mathrm{~min}$.

For the qualitative data collection, the first author communicated with IBDP coordinators, MYP coordinators and counsellors in each school to randomly select students from grades 10, 11 and 12 focus group interviews (see Table 1). The coordinators were asked to ensure that the focus groups were academically mixed: one-third of high achievers, one-third middle achievers and one-third low achievers. Before the interviews, permission letters were signed by the students' parents and collected. There were three focus groups from each case, one group for each of the three grade levels. In total, there were nine focus groups from all cases. Each group was interviewed once.

All of the interviews were conducted by the lead author. She had not met any of the students before conducting the interviews. Her experience as a high school teacher helped her build rapport with the students. Before beginning the interview, the respondents were informed about the purpose of the interview and assured anonymity. With their permission, the interviews were recorded. The focus-group interview format was semi-structured to encourage students to express their views openly. The interviewer took care to keep her voice and expression neutral to avoid bias. The flexibility allowed group members to reflect on other participants' comments and to provide more information (Gall et al. 2007).

\section{Data analysis}

For the analysis of the quantitative data, means and frequencies were calculated. The KaiserMeyer-Olkin Measure (KMO) of sampling adequacy $(p<.05)$ (Cerny and Kaiser 1977; Kaiser 1974) and the Bartlett's test of sphericity were conducted for each part of the questionnaire separately. The KMO measure of sampling adequacy was .866, .866, .899 and .772 for Parts A, B, C and D, respectively. Therefore the KMO measure is above the recommended value of 0.6 for all four parts of the questionnaire. The Bartlett's test of sphericity was significant for all parts, respectively $\left(\chi^{2}[45]=899,716 p<.05, \chi^{2} 28\right]=618,180 p<.05, \chi^{2}[36]=$ $\left.712,018 p<.05, \chi^{2}[15]=215,779 p<.05\right)$. To confirm that the scales used for the current study were unidimensional, a principal factor analysis was conducted with Varimax rotation using SPSS 20.0 software. The sharp decrease from the first to the second eigenvalue was used as evidence; the ratios between these values were found to be close to 5, 3, 4 and 3 for 
Parts A, B, C and D, respectively. The following variances were explained for Parts A, B, C and D: $49.3,36.3,49.7$, and $47.3 \%$, respectively. The analysis revealed the following four factors in the instrument used for the current study: metacognitive skills, self-regulation, motivation and attitudes toward learning.

Qualitative data analysis used NVivo 8 software to conduct a content analysis of transcribed data and to identify key major themes. For these themes, an a priori code list was used: metacognitive skills, self-regulation, motivation and attitudes toward learning. The lead author conducted the original analysis, which was then cross-checked by the other two authors. The selected themes and codes were examined by an external reviewer, who is an expert in IBDP, to ensure compliance. After the themes and related content were organised, the lead author selected and translated quotations from the transcripts that exemplified the themes. The external reviewer translated the quotes as well to ensure accuracy and relevance.

\section{Findings and discussion}

The questionnaire revealed that students perceive they have metacognitive and self-regulated learning skills. Their responses regarding motivation and attitudes toward learning were positive. While the quantitative data analysis explained 'what' students think about their pre-IBDP programmes, the qualitative data analysis provided insights into 'how' the programmes developed skills in the cognitive and affective domains. Furthermore, the focus groups provided insights into students' perceptions of how the programmes improved their metacognition and self-regulation and influenced their motivation and attitudes towards learning.

\section{Students' perceptions on how their pre-IBDP experiences develop the cognitive domain.}

Overall, the mean responses of students in all three programmes perceive that their preIBDP preparation supported their learning strategies. In particular, they agreed that they use metacognitive techniques such as questioning what they learn, creating outlines and diagrams and relating what they learn to other materials and information. Mean responses to items related to selected metacognitive techniques are found in Figure 1.

The analysis of the interview results gave insights into questionnaire response items. In the questionnaire, students indicated that they make sure they keep up with the weekly reading and assignments, $\left(N_{\text {MoNEP }}=43,75 \%, N_{\text {IGCSE }}=61,84 \%, N_{\text {MYP }}=120,72 \%\right)$. During the interviews, students from all the case study schools confirmed that they work regularly on their coursework assignments. They commented that the amount of time they devote to coursework depends on the type and quantity of class assignments. Students from MoNEP and MYP said they receive coursework almost every day.

Case MYP students discussed having to learn to manage their time better to handle all the course assignments. This was true for the other cases as well. One of the grade 10 IGCSE students reported:

My time management skill has been improved. I learned how to become more organised. Before I started IGCSE, I was playing games when I am home and the coursework was just taking half an hour. 


\section{Students' Perceptions of Metacognitive Skills}

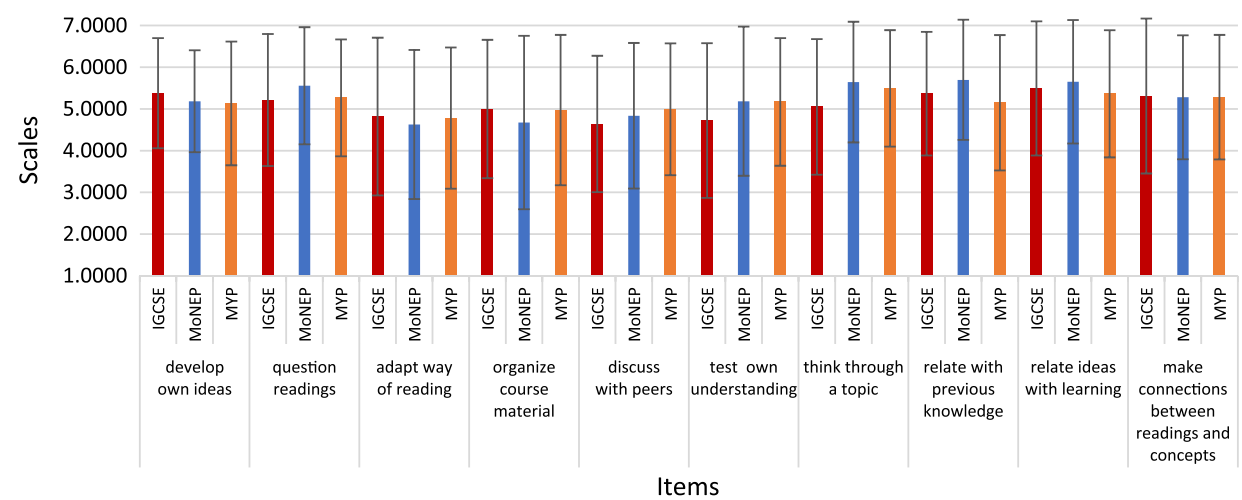

Figure 1. Student perceptions of their metacognitive skills (mean responses) from three pre-International Baccalaureate Diploma programmes.

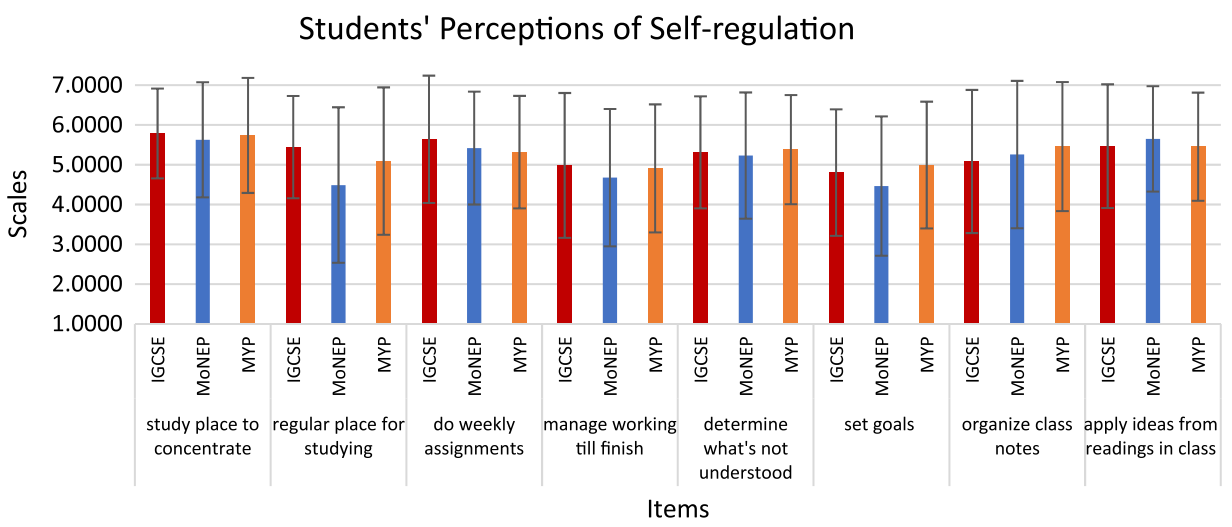

Figure 2. Student perceptions of their self-regulation (mean responses) from three pre-International Baccalaureate Diploma programmes.

Case MoNEP students mentioned that knowing they plan to enrol in the IBDP does encourage their teachers to conduct classes like an advanced international programme. They said that in tests taken during their preparatory courses, teachers would often include questions from past IBDP examinations. Students from the other Cases agreed that knowing they were preparing to enter IBDP encouraged them to develop good learning strategies.

Although student responses from all Cases regarding regulating their learning were positive (see Figure 2), a one-way ANOVA of the scales did reveal that the means of three items were significantly different among the schools:

- When asked if they believe they have the ability to understand very difficult readings in their courses, it appears that IGCSE responses were significantly different from the other case study schools, $F(2,220)=4.31 ; p=.02$. A post hoc Tukey test showed that IGCSE students' perspectives differed significantly, at $p<.05$. They reported feeling 
more certain $(M=5.28, S D=1.46)$ on their ability compared to $\operatorname{MoNEP}(M=4.44$, $S D=1.75)$ and $\operatorname{MYP}(M=4.63, S D=1.65)$ students.

- IGCSE students had significantly different responses from the other students regarding their confidence to do an excellent job on the assignments and tests in their courses $F(2,220)=3.79 ; p=.02$. The post hoc Tukey test showed the IGCSE response $(M=5.17, S D=1.33)$ was significantly higher $(p<.05)$ than that of MYP $(M=4.53$, $S D=1.54)$ students. The MoNEP was not significantly different from the other two cases, lying in the middle at $M=4.67, S D=1.51$.

- Regarding whether they set aside a regular place for studying, IGCSE student responses were significantly different than the other cases, $F(2,222)=3.81 ; p=.02$. A post hoc Tukey test showed that IGCSE students' perspectives $(\mathrm{M}=5.44, S D=1.28)$ differed significantly higher at the $p<.05$ from MoNEP students $(M=4.49, S D=1.96)$. The MYP mean was between the other two cases and was not significantly different $(M=5.09, S D=1.85)$.

- When asked if they prefered course materials that arouse their curiosity, it was the MoNEP students who had significantly different responses, $F(2,218)=4.75 ; p=.01$. The post hoc Tukey test showed that their perspectives $(M=5.93, S D=1.13)$ were significantly higher $(p<.05)$ than those of MYP $(M=5.19, S D=1.55)$ students. IGCSE student means were between the other two case study results and were not significantly different $(M=5.62, S D=1.30)$.

- Three programmes also showed significant difference, $F(2,213)=3.48 ; p=.03$, about the extent to which students consider learning new concepts in an academic year as important. A post hoc Tukey test showed that the MoNEP students' perspectives $(M=4.48, S D=0.71)$ differed significantly more at the $p<.05$ level from those of MYP $(M=4.08, S D=0.91)$ students. IGCSE students were not significantly different from the other two cases, lying in the middle at $M=4.25, S D=0.81$.

In conclusion, it appears that IGCSE students report they are confident in their reading and completing assignments. One possible reason for this difference may be that for students within IGCSE programme, there is an international examination at the end of the two-year programme. During the interviews, IGSCE students frequently mentioned this exam.

The interviewees from all case schools mentioned studying for exams given in classes, but only IGCSE students mentioned any additional studying. For example, one former Case IGCSE student currently in IBDP grade 11 recalled setting time aside to review questions from past exams. Again, this may go to show that these students are more driven to pass an international exam the year before they start IBDP. As one Case IGCSE student noted:

I prefer studying in a room which is far away from technology. When I study for the exam I use my textbook to study the topics I found difficult. Then I re-organise the topics covered in the lesson according to the relation between each other.

Although Case MoNEP students do not have an international exam about content, they need to pass an exam that shows they are proficient in a second language to be eligible to register for IBDP at their school. The MoNEP students reported that they valued new learning materials that sparked their interest. Perhaps in this case, the emphasis on test preparation is stressful and students appreciate different and novel learning materials. 


\section{Students' perceptions of how the preparatory programmes influence the affective domain}

Students believe that MoNEP, IGCSE and MYP motivate them to learn. In particular, they expressed confidence the programme would prepare them for the IBDP. In fact, many reported that they feel certain that they can master the skills being taught in classes $\left(\mathrm{N}_{\text {MoNEP }}\right.$ $=43,77 \%, \mathrm{~N}_{\mathrm{IGCSE}}=60,78 \%, \mathrm{~N}_{\mathrm{MYP}}=121,66 \%$ ). During interviews, the students in grades 11 and 12 concurred and added that they were motivated to apply skills they learned in their pre-IBDP classes because they were important for succeeding in upper-high school (see Figure 3). During interviews, students shared that learning these skills improved their confidence and motivated them to learn in IBDP. Pajares and Schunk (2001) stress that if the students are confident about their learning capabilities to perform a task, they work harder to achieve at a higher level and deal with challenges more persistently.

Students noted that improving their communication skills, such as writing and presentations, especially helped them gain confidence and motivated them to learn. Self-efficacy is related with self-regulation and use of effective learning strategies. In other words, providing students with skills such as writing, research and studying gives them confidence that can motivate them to learn (McCoach and Siegle 2003). Writing is especially key for one of the main assignments of the IBDP: the Extended Essay. In this paper, students construct a detailed and persuasive argument about a problem they investigated.

Students from cases IGCSE and MYP were most vocal about their positive experiences regarding learning communication skills. In a previous study, MYP coordinators emphasised that the programme provides students with opportunities to develop communication skills, inquiry skills and ways of applying their knowledge (Ateşkan, Dulun, and Lane 2016). One grade 12 students who had been in MYP stated, 'We improved our analysis skills through the book analysis we did. Now we use this skill in IBDP'. Another student said, 'We learned how to write in a structured way. Even in mathematics, we write by using mathematical language.' In their study, the Australian Council for Educational Research (2015) found IGCSE and MYP students reported to have developed literacy and writing skills that contributed positively to their studies in IBDP. Although not as vocal, MoNEP students also

\section{Students' Perceptions of Motivation}

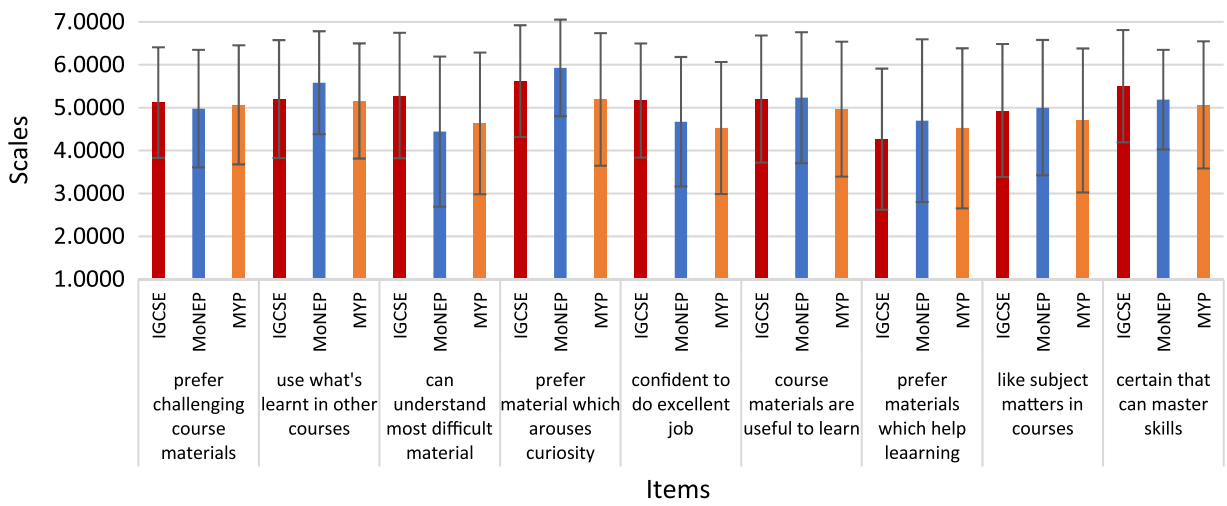

Figure 3. Student perceptions of their motivations (mean responses) from three pre-International Baccalaureate Diploma programmes. 
gave credit to their literature classes. One former MoNEP student who was now in grade 11 of IBDP stated:

This year we are writing opinion papers in our course Turkey in the Twentieth Century and our economics course. The essays we wrote in the Turkish language and literature course we took last year, are now helping us in IBDP because they improved our writing skills.

Despite some positive comments about the value of the literature classes, the MoNEP students did note that the national programme normally does not emphasise communication skills. One student stated, 'We do not have opportunities in the national curriculum to improve our speaking, essay writing and presentation skills or making mathematical links and proofs.' However, when they are on track to enrol in the IBDP, they take courses that provide them with more opportunities and experiences to improve their writing and presentation skills. One of the Case MoNEP grade 10 students shared that, "When we deliver our presentation to the class we also improve our communication skills. We express our thoughts more comfortably'.

In addition to the importance of writing skills for the Extended Essay, the students relayed that communication skills were valuable for specific courses, such as science. These skills are especially important because in the IBDP all students need to take at least one science course that includes self-directed experimental studies. Case MYP students reported that literature courses helped them improve their lab report writing skills. As one of the grade 10 currently enrolled in MYP students stated:

We learn how to write letters and essays in English language and literature course. We are expected to compose a three-paragraph document [introduction, message, and conclusion]. Teachers in other subject areas were often referring to our English and language classes. They emphasized that these [writing] skills will be important not only in English, but in other subjects.

Although students from all Cases reported that they practised lab report writing, MYP students seemed to have more opportunities. When reflecting on their pre-IBDP years, MoNEP students reported that they developed lab report writing skills, yet they were still feeling uncomfortable in the IBDP. As one of the former MoNEP students in grade 12 stated:

We were writing some sort of lab reports, however, those were not even close to the level that we write in IBDP. Writing a lab report in an academic language is challenging. It would be great if we had learned how to write a lab report that used an assessment criteria.

While all cases mentioned writing skills as a motivator, only MYP students discussed the importance of the research skills they gained in their pre-IBDP experience. One student said that, 'I learned that if I am proposing an argument then I also need to ask "why and how" questions. We basically learned how to relate cause and effect.'

Another learning motivator for students is if they realise they can transfer what they study in one class to another or to their lives (Ormrod 2006). Therefore, students were asked how they have been able to use knowledge or skills they learned in one course in another course. The questionnaire results also showed that a high proportion of the students surveyed, $\left(N_{\text {MoNEP }}=43,86 \%, N_{\text {IGCSE }}=51,73 \%, N_{\text {MYP }}=121,72 \%\right)$ agreed that they would be able to use what they learned in a course in other courses. Interdisciplinary programmes relating one subject area to another may be a source of motivation. One of the grade 12 IBDP students from Case MYP stated: 


\section{Students' Perceptions of Attitudes and Behaviours}

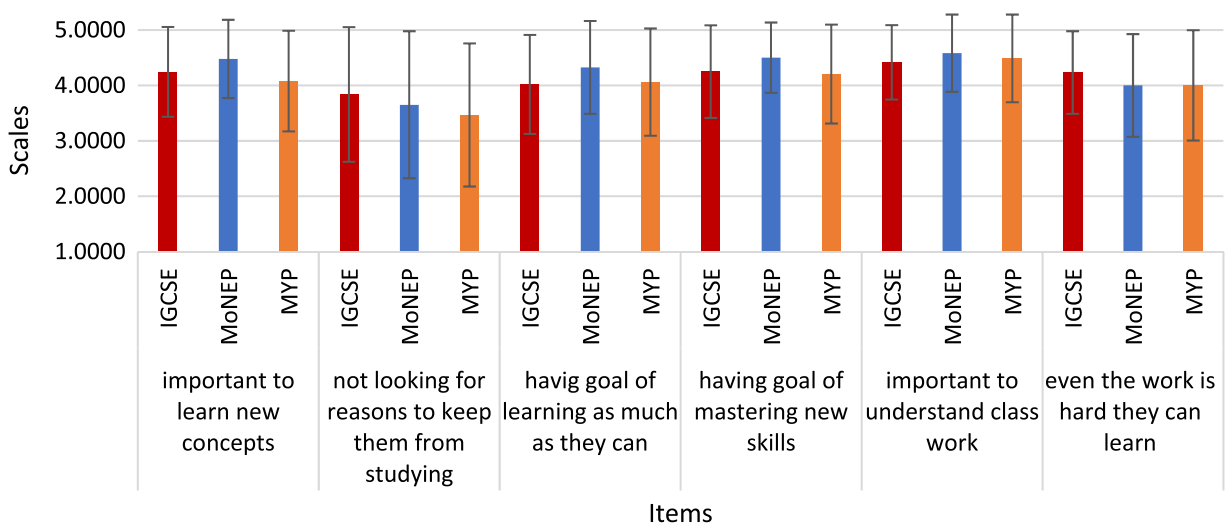

Figure 4. Student perceptions of their behaviours and attitudes towards learning (mean responses) from three pre-International Baccalaureate Diploma programmes.

You may not recognise the interdisciplinary link in MYP; however I know that in science and history courses I used the discussion skills I developed in English language and literature course. Also, I remember that we were using our scientific and historical knowledge when we were writing our arguments in the literature course. This was how we link the courses with each other.

The current and former MoNEP students did not recall courses that were purposefully interdisciplinary. One of the grade 12 IBDP students stated:

Although we were in a preparatory course for IBDP, the only change was that it was taught in English. Other than this, we didn't see any relation to other subject areas.

Another motivating factor for student learning was gaining experience studying for tests; this was useful preparation for taking IBDP examinations. To succeed in these exams, students need work independently and monitor their own progress. It was mainly students from case IGSCE who reflected on how hard they studied for exams. Grade 11 students reported that they used a marking scheme from past exam questions to study. The ACER (2015) study confirmed that memorisation and summarising skills used in preparation for IGCSE can be applied to test-taking in IBDP.

The study revealed that support materials students gained during their pre-IBDP coursework were motivations for learning. Some students may be more motivated when they are challenged by the learning experiences (Gross 1993). Therefore, the students' perceptions on the course materials will affect their motivation towards learning. As shown in Figure 4, the questionnaire results revealed that many of the respondents $\left(N_{\text {MoNEP }}=43,65 \%, N_{\text {IGCSE }}=59,76 \%, N_{\text {MYP }}=121,74 \%\right)$ agreed that they prefer course materials that really challenge them so that they can learn new things. Furthermore, a considerable proportion of the respondents $\left(N_{\text {MoNEP }}=43,72 \%, N_{\text {IGCSE }}=60,77 \%\right.$, $\left.N_{\text {MYP }}=118,62 \%\right)$ agreed that the course materials in their classes were useful for learning. During the interviews, students confirmed that they liked hands-on materials and lab work. Importantly, the majority of the respondents $\left(N_{\text {MoNEP }}=41,90 \%, N_{\text {IGCSE }}=60,83 \%\right.$, $\left.N_{\text {MYP }}=120,75 \%\right)$ agreed that they prefered course materials that aroused their curiosity, even if it was difficult to learn. 


\section{Conclusion}

This paper investigated how Turkish high school students from three different high school programmes perceived how they were prepared for the IBDP. For this study, learning strategies that developed students' cognitive domain (metacognition, self-regulation) and their affective domain (motivation, attitudes towards learning) were investigated. Our findings support that students from all three programmes perceived they developed effective learning strategies. They explained that these strategies were effective because they helped them feel ready to participate in the IBDP. The students especially credited their pre-IBDP literature courses with developing their skills related to essay writing, data analysis, lab report writing, presentation and communication. This conclusion is a tribute to their respective programmes for giving opportunities to develop and apply skills that are aligned with the IBDP. The one area that could be developed more in IGCSE and the national programme is research skills. All students indicated that investigative skills were important for IBDP, but only Case MYP students mentioned that they had opportunities to conduct research. Research skills are considered as important for the success in the IBDP because in every course, the internal assessment is based on research. More importantly, in the Extended Essay the students must use their research skills to conduct a self-study (IBO 2018a).

Although both the ICGSE and MoNEP students indicated that test preparation helped them with IBDP exams, the nature of assessment in IBDP is different than national exams. Since students from all the cases have experienced the national programme, they could attest to the emphasis on memorisation and rote learning in their MoNEP courses. The dominance of this lecture-type, teacher-centred approach to learning limits sufficient opportunities to improve speaking, essay writing, presentation, lab report writing and research skills. According to this study, when the national programme is enhanced to prepare students for the IBDP, students report they gain useful skills to help them feel ready for IBDP. If students report that these experiences help them to be feel more prepared for a rigorous international programme, perhaps all students - whether or not they plan to enrol in the IBDP - could be given these opportunities.

Regarding the students' perspectives revealed by this study, they shared that to feel ready for the IBDP and recommend that the pre-IBDP programmes become even more skill-based. One way that IBDP students can become self-regulated learners is by developing ATL skills. These ATL skills are grouped into five closely linked, overlapped and interrelated categories to improve the quality of teaching and learning: thinking skills, communication skills, self-management skills, research skills and social skills (IBO 2015). With the exception of the last one, these are all skills the case study students mentioned as important during interviews. Students recognise that there are advanced skills they need to master to be prepared for their future careers. They value programmes that give them opportunities to develop these skills and experience how they are applied in their classes and their lives. These experiences encourage them to responsible for their own learning and spark their interest and curiosity. These experiences prepare students to become leaders in the twenty-first century.

\section{Disclosure statement}

No potential conflict of interest was reported by the authors. 


\section{ORCID}

Jennie F. Lane (D) http://orcid.org/0000-0002-7763-3813

\section{References}

ACER, Australian Council for Educational Research. 2015. The International Baccalaureate (IB) Middle Years Programme (MYP): Comparing IB Diploma Programme Outcomes of Students Who Complete the MYP and Other Middle Years Courses of Study. Bethesda, MD: International Baccalaureate Organisation.

Ateşkan, A., Dulun, Ö. and Lane, J. F. (2016). MYP Implementation in Turkey. Bethesda, MD, USA. International Baccalaureate Organisation.

Ateşkan, A., J. Onur, S. Sagun, M. Sands, and M. S. Çorlu. 2014. Alignment between the DP and MoNEP in Turkey and the Effects of the Programmes on the Achievement and Development of University Students. Bethesda, MD, USA. International Baccalaureate Organisation.

Bagnall, N. 2010. "The International Baccalaureate in Australia." Melbourne Studies in Education 38 (1): 129-143.

Berk, L. 2014. Development through the Lifespan. 6th ed. New York, NY: Pearson Education.

Cambridge, J. 2012. "International Education Research and the Sociology of Knowledge." Journal of Research in International Education 11 (3): 230-244.

Cambridge. 2016. Find a Cambridge School. http://www.cambridgeinternational.org/i-want-to/finda-cambridge-school/

Cambridge. 2018. Cambridge IGCSE Curriculum. http://www.cambridgeinternational.org/ programmes-and-qualifications/cambridge-secondary-2/cambridge-igcse/curriculum/

Cerny, B. A., and H. F. Kaiser. 1977. "A Study of a Measure of Sampling Adequacy for Factor-Analytic Correlation Matrices." Multivariate Behavioral Research 12 (1): 43-47.

Cook-Sather, A. 2002. "Authorizing Students' Perspective: Toward Trust, Dialogue, and Change in Education." Educational Researcher 31 (4): 3-14.

Çorlu, M. S. 2014. "Which Preparatory Curriculum for the International Baccalaureate Diploma Programme is Best? The Challenge for International Schools with Regard to Mathematics and Science." International Review of Education 60: 793-801.

Schunk, D. H. 1995. "Self-efficacy and Education and Instruction." In Self-efficacy, Adaptation, and Adjustment: Theory, Research, and Application, edited by J. E. Maddux, 281-303. New York: Plenum Press.

Foust, R. C., H. Hertberg-Davis, and C. M. Callahan. 2009. "Students' Perceptions of the NonAcademic Advantages and Disadvantages of Participation in Advanced Placement Courses and International Baccalaureate Programmes." Adolescence 44 (174): 289-312.

Gall, M. D., J. P. Gall, and W. R. Borg. 2007. Educational Research: An Introduction. Pearson/Allyn \& Bacon.

Gellar, C. 2002. "International Education: A Commitment to Universal Vlaues." In Interational Education in Practice: Dimensions for National and Internationl Schools, edited by M. Hayden, J. Thompson and G. Walker. London: Kogan Page.

Greene, J. C., V. J. Caracelli, and W. F. Graham. 1989. "Toward a Conceptual Framework for MixedMethod Evaluation Designs.” Educational Evaluation and Policy Analysis 11 (3): 255-274.

Gross, M. 1993. Exceptionally Gifted Students. London: Routledge.

Hill, I. 2012. "Evolution of Education for International Mindedness." Journal of Research in International Education 11 (3): 245-261.

IBO. 2015. Approaches to Learning. https://xmltwo.ibo.org/publications/DP/Group0/d_0_dpatl_ gui_1502_1/static/dpatl/guide-apr-to-learn.html

IBO, International Baccalaureate Organisation. 2017. Find an IB school. http://www.ibo.org/ programms/find-an-ib-school/

IBO. 2017a. What is an IB Education? http://www.ibo.org/globalassets/what-is-an-ib-education2017-en.pdf

IBO. 2017b. Benefits of the IB. http://www.ibo.org/benefits/

IBO. 2018a. Extended Essay. http://www.ibo.org/programmes/diploma-programme/curriculum/ extended-essay/ 
IBO. 2018b. What is the MYP. http://www.ibo.org/programmes/middle-years-programme/what-isthe-myp/

Ivankova, N. V., J. W. Creswell, and S. L. Stick. 2006. "Using Mixed-Methods Sequential Explanatory Design: From Theory to Practice." Field Methods 18 (1): 3-20.

Kaiser, H. F. 1974. "An Index of Factorial Simplicity." Psychometrika 39: 31-36.

Karadeniz, Ş., Ş. Büyüköztürk, Ö. E. Akgün, E. K. Çakmak, and F. Demirel. 2008. "The Turkish Adaptation Study of Motivated Strategies for Learning Questionnaire (MSLQ) for 12-18 Year Old Children: Results of Confirmatory Factory Analysis." The Turkish Online Journal of Educational Technology - TOJET 7(4): 108-117.

Kirk, K. 2009. Cutting Edge: Enhance Your Teaching: Affective Domain. http://serc.carleton.edu/ NAGTWorkshops/affective/index.html

Kitsantas, A., S. Steen, and F. Huie. 2009. "The Role of Self-Regulated Strategies and Goal Orientation in Predicting Achievement of Elementary School Children." International Electronic Journal of Elementary Education 2 (1): 65-81.

Li, Y., and R. Lerner. 2013. "Interrelations of Behavioral, Emotional, and Cognitive School Engagement in High School Students." Journal of Youth Adolescence 42: 20-32.

Mascret, N., A. J. Elliot, and F. Cury. 2015. "The 3x2 Achievement Goal Questionnaire for Teachers." An International Journal of Experimental Educational Psychology 37 (3): 346-361.

Matos, L., W. Lens, M. Vansteenkiste, and A. Mouratidis. 2017. "Optimal Motivation in Peruvian High Schools: Should Learners Pursue and Teachers Promote Mastery Goals, Performance-Approach Goals or Both?" Learning and Individual Differences 55: 87-96.

McCoach, D. B., and D. Siegle. 2003. "Factors That Differentiate Underachieving Gifted Students from High-Achieving Gifted Students." Gifted Child Quarterly. 47: 144-154.

MEB. 2018. Öğretim Programmeları. http://mufredat.meb.gov.tr/Programmelar.aspx

Midgley, C., M. L. Maehr, L. Z. Hruda, E. Anderman, L. Anderman, K.E. Freeman, and T. Urdan. 2000. Patterns of Adaptive Learning Scale. Michigan University. https://www.umich.edu/ pals/ PALS\%202000_V12Word97.pdf.

Monteath, P. 2015. Cambridge International Examinations, Going Global [Pdf document]. http://www. johncatt.com/downloads/ccr52_1/offline/download.pdf

Muis, K. R. 2007. “The Role of Epistemic Beliefs in Self-Regulated Learning." Educational Psychologist 42 (3): $173-190$.

Ormrod, J. E. 2006. Educational Psychology Developing Learners. 5th ed. Colorado, CO: Pearson.

Pajares, F. 1996. "Self-efficacy Beliefs in Academic Settings." Review of Educational Research. 66 (4): 543-578.

Pajares, F., and D. H. Schunk. 2001. "Self-beliefs and school success: self-efficacy, selfconcept, and school achievement." In Perception, edited by R. Riding and S. Rayner, 239-266. London: Ablex Publishing.

Pintrich, P. R., and E. V. De Groot. 1990. "Motivational and Self-regulated Learning Components of Classroom Performance." Journal of Educational Psychology 82: 33-40.

Reimers, C. 2004. "From MYP to Diploma: An Investigation into the Impact of the International Baccalaureate Middle Years Programme on International Baccalaureate Diploma Candidates." International Schools Journal 14 (2): 11-18.

Ruzek, E. A., C. A. Hafen, J. P. Allen, A. Gregory, A. Y. Mikami, and R. C. Pianta. 2016. "How Teacher Emotional Support Motivates Students: The Mediating Roles of Perceived Peer Relatedness, Autonomy Support, and Competence." Learning and Instruction 42: 95-103.

Sagun, S., and M. S. Çorlu. 2014. "Resolving the Dilemma of International School Curriculum: The Case of Biology." Eurasia Journal of Mathematics, Science \& Technology Education 10 (2): 153-158.

Suldo, S. M., E. Shaunessy, and R. Hardesty. 2008. "Relationship among Tress, Coping, and Mental Health in High-Achieving High School Students." Psychology in the Schools 45 (4): 273-290.

Tate, N. 2013. "International Education in a Post-Enlightenment World." Educational Review 65 (3): 253-266.

Thompson, J. J. 1998. “Towards a Model for International Education.” In International Education, Principles and Practice, edited by M. C. Hayden and J. J. Thompson, 276-290. London: Kogan Page. 
Visser, A. 2010. "International Education in a National Context: Introducing the International Baccalaureate Middle Years Programme in Dutch Public Schools." Journal of Research in International Education 9 (2): 141-152.

Wade, J. H., and N. L. Wolanin. 2015. A Comparison of MYP and Non-MYP Students' Participation and Performance in High School. Bethesda, MD: International Baccalaureate Organisation.

Wright, E., and M. Lee. 2014. "Developing Skills for Youth in the 21st Century: The Role of Elite International Baccalaureate Diploma Programme Schools in China." International Review of Education 60 (2): 199-216.

Yang, M. 2005. "Investigating the Structure and the Pattern in Self-Regulated Learning by High School Students." Asia Pacific Education Review 6 (2): 162-169.

Yin, R. K. 2002. Case Study Research Design and Methods. 3rd ed. London: Sage Publication.

Yumuşak, N., S. Sungur, and J. Çakıroğlu. 2007. “Turkish High School Students’ Biology Achievement in Relation to Academic Self-Regulation." Educational Research and Evaluation: An International Journal on Theory and Practice 13 (1): 53-69.

Zimmerman, B. J. 2002. "Becoming a Self-Regulated Learner: An Overview." Theory into Practice 41: 64-70. 